\title{
Direito e Justiça
}

Clenício da Silva Duarte

Consultor Jurídico do DASP

SUMARIO: 1. Que se entende por Direito. Problema do conceito. Duas correntes e três tendências. 2. Posição positivista $e$ posiçāo neokantiana. 3. Crítica das três tendências. 4. Conceito do Direito. Definiçōes. 5. Justiça. Que se entende por Justiça. 6. Fim do Direito. A Justiça como valor supremo a que aspira o Direito. Segurança jurídica. Conceito. Conflito entre Justiça e segurança.

1. O problema do conceito do Direito tem suscitado sérias divergências. Embora haja constituído preocupação dos juristas filósofos, desde há muitos anos, não apresentou, até hoje, resultados que demonstrem uma aceitação universal. 1 A dificuldade nessa conceituação está em que, como salienta RADBRUCH, "o conceito do direito é um conceito cultural, isto é, o de uma realidade referida a valores, ou ainda, de uma realidade cujo sentido é achar-se ao serviço de certos valores". ${ }^{2}$

Já KANT ${ }^{3}$ observara que "essa questão, se não se cair em uma tautologia, a menos que se refira à legislação de determinado país ou tempo, em lugar de dar uma solução geral, é tão grave para o jurisconsulto quanto para o lógico o de - "Que é a verdade".

É que - ainda dentro do pensamento de KANT, já agora citado por GROPPALI, ${ }^{4}$ - se as ciências jurídicas respondem à pergunta - quid juris? (que se estabeleceu por direito em re.

No mesmo sentido, G. DEL VECCHIO, Lezionl dl Fllosolla del Dirltto, Milăo, 7.a ed., 1950, p. 187

2

Filosofia do Direito, trad. Cabral de Moncada, 1937, p. 46. Cf., também, aut. cit., Introducción a la Filosolia del Derecho, ed. do Fundo de Cultura Económica do México,

3 Pri, p. 46

3 Princirios Melafeicos del Derecho, ed. argentina, 1943, ps. 45 e 46

4 Fllosofla del Diritto, Milð̌o, 1944, p. 140 
lação a determinada questão?), não contestam a pergunta quid jus? (Que é o direito?), sendo esta última, precisamente, a que interessa à ciência ou teoria geral e à filosofia do direito. ${ }^{5}$

O problema do conceito do Direito, entretanto, embora não possa apresentar uma solução uniforme, no sentido de ser aceito por todos os juristas, pois que depende de fatores subjetivos, oriundos da posição filosófica de cada um, é evidente que sua conceituação é de grande utilidade.

Para quem se inicie no estudo da filosofia do direito, essas considerações são algo chocantes, porque o leva a uma conclusão pessimista e um tanto cética, no sentido de que os problemas por ela levantados são, praticamente, insuscetiveis de solução universal, isto é, de uma resolução em definitivo, aceita por todos. Pode, assim, dizer-se que o único ponto em que estão de acordo os jusfilósofos é o de que não há qualquer possível acordo... É que o objetivo da filosofia é o de, precisamente, levantar problemas.

Há, todavia, em relação ao conceito do Direito, duas correntes do pensamento filosófico que se disputam a primazia de uma conceituação e que são as seguintes: a) a dos que entendem não ser possível estabelecer-se um conceito universal do Direito - os céticos e os agnósticos; b) a dos que sustentam 0 contrário - os positivistas e os idealistas.

A primeira corrente sustenta que, dadas as diferenças dos ordenamentos jurídicos e as discordâncias dos juízos em relação ao valor do justo, é impossivel chegar-se a um conceito do Direito, universalmente aceito e válido para todos esses sistemas. É que, havendo discordância, no que concerne aos variados sistemas jurídicos, do que é justo e injusto, chegam os céticos à conclusão de que esse valor não existe por si na natureza, mas apenas segundo os determinados sistemas jurídicos. Se esse valor existisse por si mesmo, como derivado da natureza sustentam eles - teríamos todos o mesmo conceito do justo e do injusto, como temos do quente e do frio, do doce e do

\footnotetext{
5 "Noch suchen die Juristen eine Definition zu ihrem Begriffe von Recht" (Os juristas ainda buscam uma definiçăo para o seu conceito de direito), KANT, Kritik der reinen Vernunft, apud HAESERT, Théorie Générale du Drolt, Bruxelas, 1948, pritik 67.

R. Serv. Públ., Brasília, 108 (2): mai./ago, 197.3
} 
amargo. ${ }^{6}$ É célebre a máxima de PASCAL, que asseverou bastar três graus de latitude para destruir toda uma jurisprudência.

A segunda corrente, embora admitindo um conceito universal do Direito, vale dizer, um conceito do Direito comum a todos os direitos, estando, assim, de acordo quanto à possibilidade desse conceito, apresenta, no entanto, divergências que a fazem subdividir-se em dois grupos: os positivistas e os idealistas ou neokantianos. Esse antagonismo que se encontra nesta segunda corrente deve-se ao fato de uns admitirem que a realidade deve ser contemplada fora de nós e, outros, que ela está em nós. ${ }^{7}$ É, como adverte GROPPALI, ${ }^{8}$ a mesma divergência que, mutatis mutandis, dividia os nominalistas dos realistas, pois que, embora se mudem os termos e modos em que se ponham e se discutam os problemas, não mudam eles, no entanto, de natureza.

2. Entendem os positivistas que só as manifestações individuais e concretas do Direito têm uma existência objetiva fora da consciência, preconizando o método indutivo para a coleta de dados que fornecerão elementos para a conceituação do $\mathrm{Di}$ reito. Em outras palavras, o conceito do Direito seria, assim, um a posteriori, constituindo-se, por conseguinte, num juízo empírico. Após a observação dos fenômenos jurídicos particulares, poder-se-ia, através de um processo de generalização, chegar ao conceito do Direito.

Os neokantianos, ao revés, pretendem que a realidade está em nós, só sendo possível a experiência jurídica partindo-se de um conceito do direito a priori formado. Preconizam, por esse efeito, o método dedutivo, sendo o conceito do Direito deduzido pela razão, sem qualquer concurso da experiência.

3. O ceticismo, pela sua posição negativista, não reconhecendo constantes no fenômeno jurídico, o que, segundo os seus partidários, impossibilita um conceito universal do Direito, dada a multiplicidade e variabilidade dos dados a serem coligidos pela experiência, começa por cair numa contradição, pois não é

\footnotetext{
6 "Nam si esset, ut calida et frigida, et amara et dulcia, sic essent justa et injusta eadem

7 Omnibus". dado a priori (isto é, năo-empirico) e constitui precisamente a condiçăo-limite da experiencia juridica em geral".

8 Ob. cit., p. 143
} 
possível afirmar-se a variabilidade do Direito sem se possuir antes um conceito universal do jurídico, que assim permitiria reconhecer como jurídicas as formas variáveis do sistema.

Se, - como observa GROPPALI, 9 - no que concerne a alguns fenômenos, ou mesmo institutos, a variabilidade de conceito não os torna universalmente jurídicos, por contingências temporárias e acidentais, o mesmo não ocorre em relação à imensa maioria das instituições jurídicas fundamentais, que constituem patrimônio de toda a humanidade, que nelas vê a expressão do jurídico ontologicamente considerado.

Aliás o ceticismo não logrou grande aceitação, dividindo-se os juristas entre as duas outras tendências - a positivista e a criticista ou neokantiana.

Como já afirmamos acima, citando GROPPALI, essas duas tendências apenas se separam no que tange ao método, partindo uns da afirmação de que a realidade deve ser contemplada fora de nós (positivistas), e, os outros, de que a realidade está em nós (neokantianos).

A crítica que se pode fazer a essas duas grandes tendências da moderna filosofia do direito é que, quanto ao positivismo, esta corrente coloca em contraposição radical o fenômeno jurídico empírico com a idéia, quando esta, necessariamente, é um pressuposto daquele. É que, para constatar-se o fenômeno jurídico, imprescindível se torna que o observador já traga em si a idéia do Direito, pois, do contrário, não poderia fazer distinção, no coligir os dados de sua experiência, entre o que é jurídico e o que não o é Se admitem os positivistas que o conceito do Direito deve ser conseguido através de generalizações dos dados fornecidos pela experiência jurídica, é que - e isso é evidente - admitem que o observador possa distinguir, entre os dados encontrados, os que devam ser coligidos, por serem jurídicos, pressupondo, assim, que esse observador já traga em si a idéia do Direito, pois que, do contrário, seria impossível a distinção.

Quanto aos neokantianos, também se Ihes critica o fato de que, se, de posse de um conceito a priori do Direito, procuramos

9 Ob. cit., p. 142

R. Serv. Púb!., Brasília, 108 (2): mai./ago. 1973 
com ele distinguir, na prática, o direito dos demais fenômenos sociais, corremos o risco de não encontrar a comprovação desse conceito Isso, pelo simples fato de que, com esse conceito a priori do Direito, que levamos para a constatação dos fenômenos jurídicos, poderíamos excluir formas jurídicas que se não enquadrassem nessa concepção apriorística, verificando-se, então, que, ao invés de conseguirmos um critério do Direito comprovado pela experiência, teríamos uma noção que se pretenderia impor à experiência.

Pela exposiçạ̃o feita das duas grandes tendências (a positivista e a neokantiana), vemos que, se, de um lado, a escola positivista entende que o conceito do Direito só pode ser inferido a posteriori, pela indução dos fenômenos jurídicos isolados para chegar-se ao conceito do jurídico; de outro, a escola neokantiana parte da exigência de um conceito a priori, para, pelo método dedutivo, dizer dos fenômenos jurídicos enquadráveis nesse conceito. E, assim, tem-se que, pela primeira escola, cai-se num círculo vicioso, pois que, para separar dos fenômenos sociais os que sejam somente jurídicos, necessário se torna que o observador leve para a sua experiência um conceito preformado do jurídico; do contrário, ficará impossibilitado de fazer a separação imprescindível, pois que não dispõe de elementos que o habilitem a realizar a indução desejada, pela impossibilidade de caracterizar os fenômenos a observar, não podendo, por esse efeito, chegar ao conceito que formaria após essa indução.

A segunda escola, por seu turno, partindo de um conceito a priori, pode também, como já vimos, não lograr êxito na sua dedução, do momento em que os fenômenos que se não enquadrem no conceito preformado do observador poderão por ele não ser considerados como jurídicos, embora enquadráveis como tais em outro conceito, também apriorístico, de outro observador. $E$, assim, também não leva à solução do problema.

Desse modo, entendemos que o conceito do Direito não poderá ser conseguido através do emprego exclusivo de qualquer desses métodos. O problema - parece-nos - só poderá Ser resolvido pela aplicação concomitante dos dois métodos. Terá, assim, o observador que levar, como princípio de observação, um conceito a priori do Direito, mas tal conceito não será definitivo, podendo sofrer alteração com os dados da experiên- 
cia, à medida que se forem fazendo sentir sobre o observador. $E$ este, verificando não se enquadrarem os dados no seu conceito apriorístico, ao constatar que os fenômenos observados devem ser conceituados como jurídicos, modificará o conceito que levou já formado para a experimentação, adaptando-o a essa nova experiência realizada, para o fim de aproximá-lo o mais possível do verdadeiro conceito do Direito. O método a empregar, segundo entendemos, deverá, pois, ser o dedutivo-indutivo. Prevalecerá o primeiro que, entretanto, sofrerá a influência do segundo.

4. Para RADBRUCH, 10 "o direito é um fato ou fenômeno cultural, isto é, um fato referido a valores". O conceito do Direito, para o saudoso jurista, só pode ser determinado pelo "conjunto de dados da experiência que tem o "sentido" de pretenderem realizar a idéia do direito". E adverte o autor citado que, embora injusto, não deixa de ser direito, "na medida em que o seu "sentido" vem a ser precisamente esse: o de realizar o justo". Termina RADBRUCH por definir o Direito como "a realidade que tem o sentido de se achar ao serviço da idéia de justiça". 11

No seu excelente livro, que resume um pequeno curso professado em 1947, na Alemanha, intitulado Introducción a la Filosofía del Derecho, 1951, RADBRUCH define o Direito como "a soma ou o conjunto dos fatos críticos cujo sentido está em realizar a justiça, quer a realizem ou não. É direito aquilo que tem como sentido pôr em prática a idéia do direito". 12

É largamente conhecida a definição de KANT, segundo a qual "o direito é o complexo de condições através das quais 0 arbítrio de cada um pode coexistir com o arbítrio de todos, se gundo uma lei universal de liberdade".

DEL VECCHIO ${ }^{13}$ critica a definição de KANT, embora tenha declarado que, em um certo sentido, é das mais perfeitas. Entende o notável professor da Universidade de Roma que, em virtude dessa definição, deveriam excluir-se, sem dúvida, da categoria de direito todos os sistemas onde igual liberdade não

Filosofia do Direito, trad. Cabral de Moncada, 1937, p. 12
Ob. cit., p. 49

Ob. cit., p. 47

Ob. cit., p. 190

R. Serv. Púb!., Brasilia, 108 (2): mai./ago. 1973 
é reconhecida. E, assim, estaria excluído o direito romano, que, com a instituição da escravidão, negava a lei de igual liberdade. 14

DEL VECCHIO, após asseverar que o conteúdo da realidade jurídica não pode servir de base para uma definição do Direito, pois que este, por sua natureza, é condicionado a acontecimentos mutáveis, donde a impossibilidade de nos valermos dessa realidade variável para fixar a noção do Direito, ${ }^{15}$ define-o como "coordenação objetiva das ações possíveis entre vários sujeitos, segundo um princípio ético que a determina, excluindo-lhe o impedimento". 16

KELSEN 17 entende que, "como categoria moral, o Direito equivale à Justiça. É esta a expressão para a ordem social absolutamente justa; uma ordem que alcança perfeitamente seu objetivo enquanto satisfaz a todos. $\mathrm{O}$ anelo da justiça é - psicologicamente considerado - o eterno anelo do homem pela felicidade que, como ser individual, não pode encontrar, e, no entanto, procura na sociedade. Chama-se "Justiça" à felicidade social". 18

Pelas definições que transcrevemos acima, nota-se que não há uma conceituação uniforme por parte dos autores, embora possamos observar que, de um modo geral, tais conceitos se orientam no sentido da Justiça.

Mais adiante, ao focalizarmos o problema da finalidade do Direitto, procuraremos firmar o nosso ponto-de-vista a respeito.

Podemos adiantar, no entanto, que, com RADBRUCH, ${ }^{19}$ admitimos que o Direito é um fenômeno cultural e, conseqüentemente, o conceito do Direito há que ser referido a valores.

5. Pelas definições do Direito que alinhamos acima, vê-se que este deve ser orientado pela Justiça. Mas que vem a ser a Justiça? Qual o seu conceito?

\footnotetext{
14 No mesmo sentido, GROPPALI, ob. cit., p. 142, que observa o grande equíroco da definição, que exclúiria um dos ordenamentos juridicos mais perfeitos que já se conheceram em toda a história da humanidade.

Ob. cit., p. 192

Ob. cit., p. 208

La Teoria Pura del Derecho, Buenos Aires, 1946

Introducclón cit., p. 46

Introducción cit., p. 46
} 
Como observa RADBRUCH, "a Justiça é um valor absoluto, como a verdade, o bem ou a beleza. É um valor que descansa, portanto, em si mesmo, não derivando de outro superior". ${ }^{20}$

No mesmo sentido, pronuncia-se KELSEN: "Em seu autêntico sentido, diverso do de Direito, "Justiça." significa um valor absoluto. Seu conteúdo não pode ser determinado pela Teoria pura do Direito. E mais: em nenhum caso é acessivel ao conhecimento racional, como o prova a história do espírito humano, que há muitos séculos se esforça em vão pela solução desse problema". ${ }^{21} \mathrm{E}$, mais adiante, diz-nos KELSEN: "E, assim como é impossível - segundo já se pode presumir - precisar a essência da idéia ou da coisa em si, como conhecimento científico, isto é, como conhecimento racional orientado para a experiência, também é impossível responder, por igual, à pergunta sobre em que consiste a Justiça". ${ }^{22}$

A manifestação da Justiça está na idéia de igualdade. RADBRUCH diz: ${ }^{23}$ "A medula da justiça é a idéia de igualdade".

Mas, como igualdade, a justiça só existe no momento em que o Direito é considerado in abstracto, como quando se estatui que todos devem ser considerados iguais, independentemente do credo religioso, da raça, dos ideais políticos, etc.

6. Admitindo-se que a Justiça varia em seu conteúdo e que o Direito, para ser válido, deve realizá-la, por ser o seu fim supremo, o valor mais elevado na respectiva escala axiológica, temos, como verdade irretorqüível, que a realização desse objetivo fundamental não se efetiva em termos abstratos, - istc é, considerada a Justiça como valor ideal, independentemente do ordenamento jurídico positivo que se tenha em vista, - sem que se vulnere outro valor importante, embora hierarquicamente
inferior, que é à segurança jurídica.

Por esse efeito, se, de um lado, o fim do Direito é realizar a Justiça em termos abstratos, de outro esse desideratum, como
todo ideal, é inatingível, porque não se consegue um sistema 
jurídico positivo tão perfeito que atenda inteiramente a todos os pressupostos do conceito in abstracto de Justiça. Nem esse conceito encontraria, mesmo assim considerado, unanimidade de concepções que o identificassem uniformemente.

Se a realização da Justiça como ideal é impossível sem vulnerar-se a segurança jurídica, a consecução desse valor supremo, dentro do conceito em que é tido no sistema jurídico de que se trate, é totalmente viável, sem que se alcance éssa segurança.

Por segurança entendemos a certeza de que o direito objetivo, como previsto no ordenamento jurídico considerado, será exeqüivel, dentro dos postulados que o informam e segundo os princípios que disciplinam a hermenêutica jurídica.

Ainda que essa certeza seja um tanto relativa, pela complexidade do processo hermenêutico, constitui-se no fundamento do Direito, que não a tem por finalidade, mas como pressuposto mesmo de sua existência. É possível uma ordem jurídica injusta, mas não se concebe uma ordem jurídica inteiramente insegura. A total insegurança jurídica de um dado sistema importaria na inexistência desse sistema.

A segurança jurídica não é fim, mas condição de executoriedade do Direito, vale dizer, sem segurança não se pode falar em ordem jurídica positiva, mas num total arbítrio próprio ao despotismo.

Essa segurança, entretanto, há que ser entendida em termos, como um mínimo de condições para garantir-se estabilidade da ordem jurídica positiva, dentro dos princípios que nortearam o sistema filosófico-jurídico de que se cogita, para alcançar-se o ideal de Justiça a que visa o Direito, como sua aspiração suprema.

Dentro dessa ordem de considerações, definimos o Direito como a realização da Justiça, dentro dos limites da segurança que Ihe é imprescindivel.

O conflito entre Justiça e segurança só ocorre quando se toma a Justiça in abstracto, de lege ferenda, porque, de lege lata, 
vale dizer, a Justiça que deflui do sistema positivo considerado, não há esse conflito, porque a segurança já pressupõe a sua atuação livre.

Há assim, pois, dois conceitos de Justiça: um, absoluto, que a identifica com o valor supremo do Direito, tomado in abstracto, e outro relativo, segundo o que se infere do ordenamento jurídico de que se origina. $O$ primeiro é uma aspiração só atingivel teoricamente; o outro é uma realidade praticamente alcançável, mas que destoa do ideal do justo, filosoficamente considerado.

Por isso, seria justo, de lege lata, por exemplo, a escravidão, no direito romano, embora, de lege ferenda, segundo 0 ideal jurídico, o instituto fosse uma iniqüidade. 